\begin{tabular}{ll}
\hline \hline MINING AND METALLURGY INSTITUTE BOR & ISSN: 2334-8836 (Štampano izdanje) \\
UDK: 622 & ISSN: 2406-1395 (Online) \\
\hline \hline
\end{tabular}

\title{
DIGITAL TRANSFORMATION IN THE MINING ENTERPRISE: THE EMPIRICAL STUDY
}

\begin{abstract}
Digital transformation (DT), as a result of digitalization process, rapidly and fundamentally changes the business entities and organizations, which involves a radical review of the use of technology to change the strategy, value streams, operations, and business models, with a significant impact on customers, business partners and employees. Enterprises are launching the DT initiatives examining the wishes and needs of customers and creating operational models that use the new opportunities to increase competitiveness. In this regard, the key responses to changes in the digital era are the reshaping customer value propositions and reconfiguration the operation model. In the basic industries, where the product is mainly a raw material, such as the mining industry, the companies launch the DT initiative to improve operations. The operating model is adjusted so that user preferences and expectations affect each activity in the value chain. This requires the integration of business activities and the optimization of the way to manage and track data related to each key activity in the value chain. However, although there is a great potential for future growth, the current state of digital transformation in mining is at a low level. Therefore, the question arises as to how to launch and effectively realize the DT initiative for improvement the operational model in the mining enterprise. This paper, in general, discusses the importance of the DT, with particular reference to the key aspects of the DT, challenges and success factors in the mining industry. As a result of research, the key aspects of realization the DT initiative for improving the operational model in the large, diversified mining enterprise are presented; challenges and success factors are identified and classified in a given context. The complete research efforts, as well as the obtained results, are dedicated to the role and significance of the DT phenomenon in the mining industry, with the goal of wider and more effective use the digital technologies in the mining enterprises.
\end{abstract}

Keywords: digital transformation, challenges, success factors, mining, empirical study

\section{INTRODUCTION}

Digital technologies, such as mobile, cloud, big data, analytics, sensors, IoT (Internet of Things) and artificial intelligence (AI), with the possibility of combining them in innovative ways, exponentially accelerate the progress through the digitalization process with a great impact on business and society [1]. Considering that DT, as a result of the digitalization process, permeates all aspects of society, it may be defined as a "business model driven by the changes associated with the application of digital technology in all aspects of human society" [2].

The DT involves an integration of digital technologies in all areas of business, whereby at a high speed and thoroughly changes the way in which an organization carries out its business operations and delivers value to customers.

\footnotetext{
* Company Boksit, Milicii, Republic of Srpska, Bosnia \& Herzegovina

${ }^{* * *}$ University of Novi Sad, Faculty of Economics, Subotica, Serbia
} 
Companies implement the DT initiative changing the way they work, learn, communicate and collaborate, in order to 1) identify more easily the values relevant to customers - what is being offered, and 2) redesign the business and operational models on the basis of new possibilities how it is delivered, all with the aim of increasing competitiveness $[3,4,5,6]$.

Although the DT can be realized using different digital technologies in different scenarios, it has more implications for the business transformation of the enterprise than on the technological infrastructure itself, changing business processes and business models, which has a significant impact on organizational culture and employees $[7,8,9,10]$.

In order to successfully respond to the market changes, the companies radically reconsider the use of digital technology to improve the customer experience, operational processes, business models and business strategies $[6,9,11,12,13,14,15,16]$, focusing on one of the aforementioned areas and applying the specific initiatives, wherein some industries much more rapidly find ways to implement the DT initiative than in others [17]. However, each enterprise must individually find the best way for the DT, depending on its strategic goals, industrial context, competitive pressure, and customer expectations. Also, there are unique combinations of individual industries and their contribution to national economies in different countries, and as a result, the DT has different characteristics, while digital strategies have different objectives, even when looking at the same industries in different parts of the world $[3,18]$.

In basic industries, that offer physical products, semi-products or raw materials, such as mining, DT generally starts with initiatives that aim to improve operations, i.e. internal processes. The operating model is aligned with customer preferences and requirements so that it affects each activity in the value chain. This requires the integra- tion of all business activities in the value chain and the optimization of the way in which these activities are monitored and managed [3].

Great expectations are when it comes to the future of digitalization in mining. In this regard, it is expected that the application and connection of devices and things containing electronics, sensors, and software for mutual communication and data exchange over the Internet or in some other way will be of special importance [19].

Among the various potential benefits of digital transformation in mining, the possibilities for using digital technologies in improving the quality management process, maximizing productivity, improving working conditions and product quality are highlighted [20]. In all this, it is necessary to avoid traps, such as lack of resources, knowledge, cooperation, lack of awareness about the importance of digitalization and its underestimation [21], on the one hand, and so-called productivity paradox, that is, the situation of non-selective application of new technologies which leads to increased complexity and productivity decline, on the other hand [22].

Existing findings from the relevant literature indicate the great potential and low level of the current state of the DT in the mining industry. Therefore, the question arises as to how to initiate and effectively implement the DT initiative in the mining enterprise. In this regard, having in mind the observed lack of DT research in the mining industry, this paper aims to better understand key aspects related to the initiation and realization of the DT initiative in the mining industry, along with identifying challenges and success factors in a given context. For this purpose, empirical research was conducted on the implementation of the DT initiative in the mining enterprise.

The rest of the work is structured as follows: Section 2 presents the prevailing attitudes in the relevant literature, and Section 3 defines research questions and describes the 
applied research method. In Section 4, the results of the conducted empirical research a descriptive and explorative case study of the implementation of the DT initiative in the mining enterprise - were presented. Section 5 specifies the research limitations, and finally, conclusions are drawn and future works delineated.

\section{RELATED WORK}

DT is a complex process that is difficult to understand $[9,22]$ and is viewed differrently in different companies and industries due to different visions, stakeholders, values and levels of maturity [14], as well as due to differences in customer expectations and degree of development of existing systems. Therefore, every industry, under the pressure of inevitable changes applies different ways of implementing DT [3].

Accordingly, there is no one, generally accepted definition of the DT. For Raab et al. [7] the DT is more a matter of business transformation of the entire enterprise and less technology. Westerman et al. [11] define the DT as "the use of technology to radically improve performance or reach of enterprises", while Fitzgerald \& Kruschwitz [12] see the DT as the use of the new digital technologies (social networks, mobile, analytics, cloud, and IoT, also known under the acronym SMACIT) to enable a significant business improvement - enhancing customer experience, streamlining operations or creating new business models. For Konde \& Tundalwar [4], DT is the integration of digital technologies in all business segments, which fundamentally changes the way of working and delivering values to customers. That is partly in line with Osmundsen et al. [15] attitude that the DT is the result of digitalization or digital innovation process, which "enable major changes to how business is conducted, leading to a significant transformation of an organization or an entire industry".
On the other hand, Liere-Netheler et al. [9] observe a broader context and define the DT as a ,metamorphosis that is based on the intensive combination of present and future technologies that will change the paradigm of how value-generating processes in and between enterprises as well as with customers take place. DT will affect business models and corporate strategies.".

\subsection{Challenges of DT}

The DT is a complex venture that brings with it significant challenges, so several authors have been dealing with challenges of DT in different industries and organizations. Starting from the point that the key for successful DT is a review of the vision and initiation of changes in the business model, Westerman et al. [11] argue that the most significant challenges are related to the management and employees, not just the technology, regardless of whether the new or old technologies are applied. They classify challenges by implementation phases on: initiation challenges (lack of impetus, regulation and reputation, unclear business case), execution challenges (missing skills, culture issues, ineffective IT) and governance challenges (incremental vision and coordination issues). Depending on whether DT has the focus on reconfiguring customer value or customer modeling, Berman [3] sees the key challenges as monetization of the new proposals in offering value to the customers or defining business requirements to improve operations.

For Earley [22], challenge is not only to recognize innovative technology, but also how to apply it in an existing business model, taking into account increase in the level of additional costs for the new tools and infrastructure, while avoiding the so-called productivity paradox - a situation that the new technologies, in the given context, increase complexity to such an extent that reduces productivity. In this regard, given 
the complexity of DT, Early, as a big challenge, sees the making of the right decisions regarding the adoption of new technologies.

Emphasizing the importance and value of data in Industry 4.0, De Carolis et al. [23], as the most important challenges for traditional manufacturing companies, see the creation of awareness of the added value that DT brings, and then managing large amounts of data and information. In connection with the growing significance of data Erjavec et al. [8] note that the biggest challenge for digitization is people's problems due to the adoption of new technologies, and as an additional challenge, they note a lack of flexibility in the existing IT infrastructure, especially when it comes to collecting and processing unstructured data from different sources, and connecting existing systems with a new front-end systems.

On the other hand, Nahrkhalaji et al. [14], exploring non-profit organizations, notes that along with organizational, strategic and managerial challenges, a critical challenge in the digitization process is the change in the organization's culture, since the engagement of new IT staff and the CDO (Chief Digital Officer) does not guarantee success. Wolf et al. [21] as the main challenges, or obstacles for the DT success, see isolated thinking, poor knowledge management, underestimation of digitalization, lack of knowledge and resources, and lack of awareness about the importance of digitalization.

\subsection{Challenges of DT in the mining industry}

The mining industry has been confronted with the generic challenges since its emergence, such as an increasingly old workforce, high operating costs, a reduction in the quality of ore deposits and difficult working environment. The DT is a significant initiative that can contribute to over coming these challenges, but it requires hard work, investment, wisdom and patience [6]. Gao et al. [6] have observed that while the DT accelerated changes, many companies are not agile enough to respond to these changes, while those who fail to recognize this opportunity are faced with different challenges in an attempt to apply complementary improvements competitively in different parts of the enterprise. In this regard, they identify the following challenges in terms of how companies in the metal and mining industry are able to take advantage of opportunities to improve business operations using digital technologies: lack of competencies (unwillingness for radical change, lack of staff, commitment and investment), goal ambiguity (obsolete skills and governance model, unclear expectations and scope of change, lack of focus), technological constraints (poor connectivity, cyber threats, lack of the IoT standards, inapplicability or immaturity of technologies, redundancy due to mistrust) and external constraints (complex operating environment, safety, legislation, social responsibility).

Exploring global trends in the mining industry, Deloitte [24] said in its annual report that the lack of staff in the mining industry with digital knowledge and competencies undermines the digitalization process, and therefore, the challenge is to attract digitally competent staff from other industries.

Ernst \& Young [25], in their article dedicated to DT in mining, emphasize the importance of the so-called digital disconnection, as a gap between the potentials of digital transformation and lack of data and knowledge of successful implementation examples, in order to overcome the growing challenges of increasing productivity, access to capital, increasing transparency, maintaining licenses (concessions) and cybersecurity. 


\subsection{Success factors of DT}

Several researchers dealt with the factors of success of digital transformation, both from the perspective of the organization, as well as from the perspective of customers [16]. While Berman [3] argues that companies with a cohesive plan for the integration of digital and physical components of operations can successfully transform their business model, for Westerman et al. [17] leadership capabilities are the key to a successful implementation of DT, i.e. to convert a digital investment into a digital asset. This is supported by Earley [22], for which the leadership implies developing a viable vision of digital experience, whether for internal or external users. In doing so, the digital experience must influence the content and functionality adjustment to the current needs of users. In all this, the data play a crucial role, so organizations need to manage data and information as a strategic resource.

Khan [26] as a key factor of DT sees leadership capabilities for successful operationalization and implementation of DT, whereby framing the digital challenge, focusing investment, mobilizing the organization (creating a sense of urgency) and sustaining the transition is crucial for operational leadership. Sebastian et al. [27] identify three main elements for a successful DT: a digital strategy - that defines a value proposition based on digital technologies, an operational backbone - that facilitate operational excellence and a digital service platform which enables rapid innovation and responsiveness to new market opportunities.

Bearing in mind the need to optimize the process applying the tools, concepts and, most importantly, involving people for de Sousa et al. [20] it is crucial to raise awareness and training, both the managers and the employees. This may contribute to the easy access to data and reports, and monitoring in real time. For Erjavec et al. [8] the key for a successful DT is a cultural change. Pflaum \& Gölzer [10] agrees with that, emphasizing the importance of creating a digital enterprise vision, matching operational goals, and see DT as a race with time, where speed depends on the existence of a digital department and a supporting business ecosystem.

According to Nahrkhalaji et al. [14], in order to raise the level of maturity, in the context of DT, organizations must review existing business models, improve the decision-making process, find the right leadership, solve the complexity and insecurity imposed by new models of competition and collaboration, and engage customers. The DT is a combination of old and new technologies, a revolution and an evolution, therefore Wolf et al. [21] as the key success factors of the DT sees the creation of innovative areas, linking across the boundaries of the organization, the application of agile methods, the motivation to try new things and active management. In addition to the initiator, goals and implycations of DT, Osmundsen et al. [15] identify the following success factors: supportive and agile organizational culture, good management of transformation activities, knowledge management, participation of managers and employees, enhancement of information system capabilities, development of dynamic capabilities, development of digital business strategy, business compliance and information system. Liere-Netheler et al. [9] propose a working framework for a successful DT, while various researchers have dealt with the success factors of individual technologies or aspects of DT, such as the user experience [16, 28,29,30].

\subsection{Success factors of DT in the mining industry}

Deloitte [24] notes that in mining there are changes in the way in which value creation is observed, how well a enterprise extracts resources, to how the enterprise 
uses the information to optimize production, reduce costs, increase efficiency and improve security. With this in mind, Deloitte [24] claims that the success of DT does not depend on the adoption of the latest applications and technologies that will continue to evolve, but from integrating the digital thinking into the very center of business strategy and business practice in order to change the way corporate decision-making. This requires the evolution of leadership competencies and a clear vision of how a future, digital mine can transform the processes of realization, information flow, and support processes.

Starting from the fact that the increase in productivity is one of the key goals in mining, in order to get DT in the right way Ernst \& Young [25] emphasizes the importance of understanding 3 key elements: harmonizing the DT and productivity agenda, end-to-end approach to business (from the markets to mines) and a focus on eliminating waste, especially when it comes to the influence of leadership and organizational culture.

Although several authors dealt with the identification and research of the challenges and success factors of DT, in general, there is a lack of research in the mining industry. Therefore, the need for further research on the DT phenomenon in the mining industry is evident, in order to overcome the gap of digital disconnection, validate existing knowledge and identify new, in different situational contexts.

\section{METHODOLOGY}

The aim of research is a better understanding of the key aspects regarding the initiation and implementation of DT initiatives in the mining industry, as well as identifying the challenges and success factors in this context. In this respect, defined the research questions are:

RQ1: How to initiate and realize the DT initiative in the mining enterprise?
RQ2: What are the challenges of DT in the mining enterprise?

RQ3: What are the success factors of $D T$ in the mining enterprise?

In order to answer the research questions, empirical research was conducted in a large diversified mining enterprise Company Boksit. For the needs of research, the case of development and implementation of the analytical business software system for organization unit (OU) Surface mines is selected (hereinafter Mining Portal). OU Surface mines is part of the Mining division and performs surface exploration of ore sites at several remote locations, with different exploitation conditions, different types and quality of ore resources.

The main purpose of the Mining Portal was to support the improvement of the operational model, i.e. improvement of key business processes in the value chain related to surface exploitation of ore sites. The development and implementation of the Mining Portal implied the application of various digital technologies, such as advanced analytics, cloud, and mobile, as well as integration with the existing ERP system and external data sources.

Combining a descriptive and explorative case study provides a better understanding of the problems in its natural environment and defining a framework for further research [31]. Therefore, the descriptive case study was first applied in the realization of the research, in order to describe the key aspects regarding the initiation and the realization of the DT initiative for the improvement of the operational model of OU Surface mines, and in order to better understand the context, motives and drivers, the purpose and objectives, the results achieved, advantages and disadvantages of the DT initiative, as well as opportunities to launch future DT initiatives. 
Subsequently, in the same context, an explorative case study was carried out to identify the challenges, success factors, and the possibilities for further research. Various sources, including documents, an implemented software system, and semistructured interviews, were used to collect data and to better understand how key correspondents see the research problem.

In order to examine the problem of research for both, business and IT perspectives, a semi-structured interview was conducted with the key persons responsible for implementing the DT initiative. From the business part, this was the Technical manager of surface mines (hereinafter Technical Manager), and from the IT part of the enterprise, one of the authors, a former CIO (hereinafter ex CIO).

KWIC (Key Word in Context), qualitative analysis, and thematic analysis were used for selection, extraction, coding, and analysis of empirical data. Qualitative analysis is used to analyze data, because it supports a more detailed description of the observed phenomenon, while qualitative data allow for better insight into the complex processes [32]. The obtained results were discussed and compared with the existing knowledge and results of similar research, both in the mining and in other industries.

Bearing in mind that one of the authors (ex CIO) was actively involved in the realization of the DT initiative, as a key IT member, in order to reduce the risk of bias, the research was carried out by two authors.

\section{RESULTS AND DISCUSSION}

In accordance with the described research method, the results of the descriptive case study are presented, which describe key aspects of the DT initiative for the improvement of the operational model in the mining enterprise by the development and implementation of the Mining Portal for OU Surface mines, as the most important part of the Mining division in the Company Boksit. In addition, the re- sults of an explorative case study are presented, which identify and discuss the challenges and success factors of the DT initiative realization in a given context.

\subsection{Key aspects of the DT initiative in the mining enterprise}

In this section, the results of a descriptive case study are presented in order to get an answer to the RQ1: How to initiate and realize the $D T$ initiative in the mining enterprise?

The presented results of the descriptive case study describe the context, motivation and initiators, the purpose and objectives, the results of the DT initiative in the form of the implemented functionalities of the Mining Portal, and the advantages and disadvantages. Finally, identified opportunities for future DT initiatives are presented. The results obtained were discussed on the basis of existing knowledge in the relevant literature.

\section{Context}

The Company Boksit was founded in 1959 as an enterprise for bauxite ore exploitation. Other activities, such as traffic, construction, mechanical and electrical engineering, catering and tourism, commercial activities, food production, furniture production, health care, etc., have been successfully developed by a continuous growth and development from the bauxite ore industry. As a threefold winner of the most successful enterprise in the Republic of Srpska, it is one of the most important companies in the Republic of Srpska and Bosnia \& Herzegovina. In its 60-year long mining tradition, over 31 million tons of bauxite ore has been produced, more than 195 million tons of waste material has been removed, and more than 3 million tons of nonmetallic raw materials (limestone, quartz sand) have been produced. Annual production of surface mines is about $300,000 \mathrm{t}$ of bauxite ore and 1.350 million $\mathrm{m}^{3}$ of waste removed, with the engagement of own and subcon- 
tractor's equipment. In order to plan, organize, implement and control business processes, ERP and QMS (Quality Management System) are used, while all key locations are connected to the LAN/WAN network [www.ad-boksit.com].

\section{Motivation and initiator of the DT initiative}

Key motivation factors for initiating the DT initiative were growing demands for information and analyzes related to the implementation of the operational process of surface exploitation of bauxite ore, in all key phases and activities, in order to improve the operational model, to establish better control, and to make faster, more effective and efficient decisions at operational, tactical and strategic levels. The required information and analyzes mostly relate to the indicators of the results and activities of the surface exploitation process, as well as the indicators of the associated processes from value chain, such as the stock of products, essential materials and raw materials, the availability of equipment, the status of the realization of current purchases, etc.

The initiator of DT in the mining sector was Technical Manager, for whom digitization is a "data revival, which in digital form can be used in a variety of ways, for various purposes, in a much faster and simpler way".

Problems of the previous situation were caused by the fact that the records related to the realization of the production and maintenance process on the surface mines were guided in paper form, because due to the limitations of the existing ER system, unlike other business processes (Purchase, Inventory, Sales, HR, Financials...), it could not be adequately parameterized and customized to support the production of bauxite ore and the maintenance of mining machinery, due to the specific nature and complexity of the process. For this reason, no automated analytical processing of operational data from the ore production process was possible, but everything was done manually. It was time-consuming and errorprone, and as a result "we needed at least 5 to 7 days to produce a monthly or annual report... it was not possible to obtain timely, accurate and reliable information" (Technical Manager).

\section{Purpose and goals of the DT initiative}

The focus of improvement was the operational model, that is, the key processes of realization in the value chain related to the surface exploitation of the bauxite ore, but indirectly in the focus was the customer, having in mind that "if timely information regarding the quality of individual deposits is available, as well as information that influence the timely taking of measures and making decisions from which parts of the deposit, when and in what quantities they are to be exploited, all together influence the dynamics of delivery, price and quality of the goods delivered to the customer" (Technical Manager).

The main purpose of the DT initiative was to improve the existing operational model enabling a faster access to information and better information flow, faster analysis and decision making, in order to achieve the goals of increasing productivity, reducing costs, better control and preventing misuse. The realization of the stated goals should have enabled the development and implementation of business software for "fast and reliable recording of data from realized business activities, and quick reporting for different time periods and different analytics" (Technical Manager).

\section{Results of the DT initiative}

Bearing in mind the shortcomings of the existing ERP system, the focus has been on the development of the Mining Portal - analytical business software system "which will work exactly as we need it and which will serve its purpose" (Technical Manager).

A so-called lean approach is applied, the essence of which is the focus on data and information that has the highest value for 
the user in a given context. In this regard, the aim was to offer the content for which the user is authorized, which has significant value for that user, which the user will find and use quickly and with minimal effort and which will be presented by clearly transmitting messages or information in a given context.
The Mining Portal is realized using the iterative-incremental approach for different segments of processes, phases, and activities, with a special focus on key activities of the highest priority, because "e.g. the activities of loading and transport of ore and waste have had greater relevance than waste disposal" (Technical Manager).

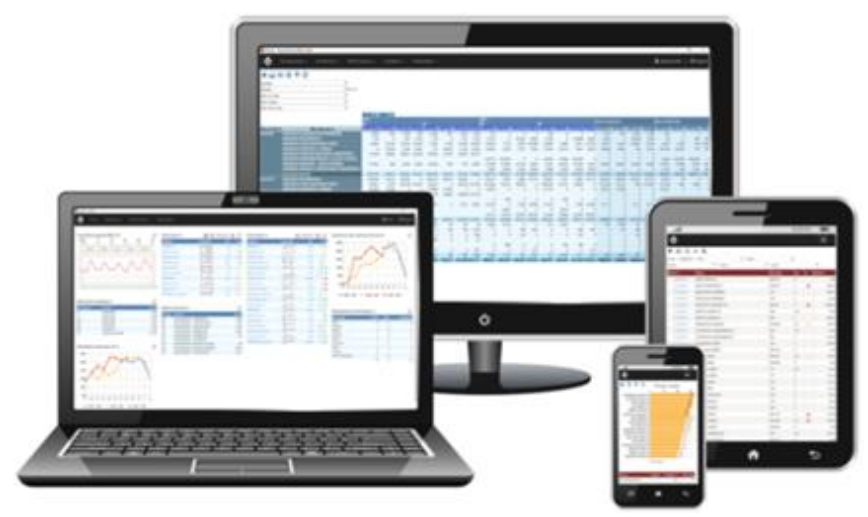

Figure 1 Mining Portal

The Mining Portal automatically adjusts the presentation depending on the user device (Figure 1) to each user, according to the privileges, providing up-to-date, accurate and clear key information on different levels of detail, which are essential for effective and efficient operational decision-making and management.

Information and data are available and accessible on the mobile phone anytime, anywhere, supporting the continuous improvement of the operations model, so as to "support better visibility of business processes and promotes operational agility and flexibility, resulting in increased productivity and reduced costs" (ex CIO). In order to enable all this, the following functionalities are implemented:

- Dashboards - as a set of several independent, personalized segments (web parts) that provide key information from internal and external sources, the purpose of which is to present key information, goals, results, time series (trends) and status at the highest level realization of defined goals. Static segments provide information in the form of a summary report, while analytical segments provide more detailed analytics and drill-down options to "combine all-in-one, intuitive presentations (dashboard) with drill-down options suitable for display on mobile devices to increase the visibility of process" (ex CIO).

- Digitization of business data - enabling effective CRUD (create, read, update and delete) of data into the database and/or existing ERP, because "efficient data digitization, with applying the rules for automated data quality control, increase the potential for their reuse" (ex CIO). 
- Performance management - various views and analytical processing of KPIs (Key Performance Indicator) provide a detailed analytical insight into the values or ratings of indicators at different levels of aggregation, because "setting measurable targets for KPIs, monitoring, reporting and control contribute to the increase in agility and sense of urgen$c y "$ (ex CIO).

- On - line analytical processing (OLAP) - to quickly generate complex reports (Web pivot tables), support projection and restriction (slice \& dice), aggregation, sorting and analyzing large amounts of data, independently of their original layout by simply dimensions and facts drag anddrop to the appropriate positions in the settings form. On-line pivot reporting, multi-dimensional calculations, and drill-down across different analytics "increase efficiency and flexibility, in the sense that the same data set can easily display in many different ways" (ex CIO).

- Automatization of scheduled reporting - periodically generating and sending pre-defined reports, alarms and notifications by e-mail, because "automation of reporting directly contributes to increasing productivity and reducing costs" (ex CIO).

- Integration with other systems - like ERP and sources of meteorological data, in order to "maximize the value and usability of the data from legacy systems" (ex CIO).

Advantages and disadvantages of the implemented DT initiative

The key advantage of the realized DT initiative is the possibility of simple and fast recording, control and integration of data, and the provision of timely and accu- rate information, which are at any time, and almost everywhere, available through the mobile phone, based on which decisions and responses are made faster in changing business conditions. High level of automation of data control reduces the probability of occurrence of errors and enables their easier detection and correction during entering of data. The results of the DT significantly influenced the improvement of the operational model, i.e. the way the business process was realized, for example, "it was noticed that the drilling system does not produce the expected results, which were directly demonstrated by analyzes based on data related to the effects, consumption, and availability of machinery" (Technical Manager). Even if the software is custom-made, due to delays in documentation delivery and recording them on a daily basis, the effects are minimized to monitor the performance and the indicators at the daily level. Enabling the recording of data closer to the source of origin would contribute to solving this problem, "e.g. machine operators can use a mobile phone to record data" (Technical Manager, ex CIO). Although from a technical point of view, such a possibility already exists, legislation requires compulsory filling of worksheets in writing. This means that the work of the operators would be doubled when it comes to recording data (paper and electronic forms).

\section{Identified opportunities for the future DT initiatives}

Future DT initiatives could go towards greater application of sensors, IoTs and automated data readings from such devices in real time, e.g. "it would be a good thing to detect and read sudden changes in machine's fuel level in real time...or the use of devices that measure idle work time to make savings and prevent misuse of machines whose effect is measured by motorcycle hours, e.g. bulldozer" (Technical Manager). 
New machines have some of the abovementioned options, but the problem is the high price and the restriction of user access to the machine's data and vendor lock-in. There are also possibilities for the application of artificial intelligence (AI) techniques "in order to deepen the analysis or to obtain new knowledge from a large amount of data" (Technical Manager, ex CIO).

\section{Discussion}

The results of the research confirm the thesis that in basic industries, such as mining, DT starts focusing on the improvement of the operational model $[3,18]$. The results also indicate the need for a proactive approach, due to growing expectations for increasing the efficiency of the process [21], in order to reduce costs, increase productivity and employee safety $[18,19]$.

Though encouraged by growing information requests from top management, it can be noticed that the DT initiative was initiated and guided by a technical manager, i.e. from middle management level, with the emphasis on the equally important role of a key IT member, what is a significantly different position relative to Westerman et al. [11] that a successful DT initiative must be guided by the top management. On the other hand, when it comes to the problems of the existing operational model, there is a noticeable need to eliminate waste, delays and insufficient flexibility in the design, structure, and implementation of operational processes, which is in line with Deloitte's standpoint [24].

Although, in general, there are different expectations of DT at different levels of the organization [21], the results point to the need to improve the operational model in order to achieve faster data access, advanced analytics, reporting and decision making in order to increase productivity, as a key operational risk in the industry mining [25], which is in line with Deloitte's standpoint [24]. In this way, the ability to re- spond to the changes quickly increases, by what Berghaus \& Back calls "digital readiness" [33].

The developed and implemented analytical software system supports the realization of the stated goals because 1) it is based on cloud and mobile technologies [30, 13, 20, 18, 24], 2) enables automation of data capture, data control and integration of data from existing systems [8,9,20,24], and 3) provides advanced analytical processing and reporting $[6,8,18,20,24]$ using personalized dashboards and OLAP tool.

Finally, although the realized DT initiative allows timely and accurate information to be obtained, it is not always possible to achieve up-to-date day-to-day reports due to various external constraints, such as the obligation to keep paper records, the limitation of access data to machine and vendor lock-in, communication restrictions on remote locations, etc. Regardless of all this, it can be noticed that the realized DT initiative creates a solid foundation and good preconditions for the wider use of digital technologies, such as different measurement and control sensors and/or IoT $[6,10,18$, 19,21,24] for more automation of data capture and real-time reporting, as well as the application of various methods and artificial intelligence techniques [8,24,34], such as, for example, machine learning. Overcoming mentioned restrictions can significantly accelerate this process.

\subsection{The challenges of DT in the mining enterprise}

This section presents the results of qualitative and thematic analysis to get the answer to the RQ2: What are the challenges of $D T$ in the mining enterprise?

Identified challenges are grouped into four categories: operationalization of business strategy, change management, effective application of technologies and external constraints (Table 1). 


\section{Discussion}

Implementation of changes in such a complex environment, such as mining, carries with it significant challenges. While Nahrkhalaji et al. [14] identify challenges, in terms of vision and strategy for the nonprofit sector, the results of the research indicate that the most important challenges in implementing the DT initiative in mining are related to the effective operationalization of the business strategy. In this regard, the key challenges are not only related to ambiguous goals, as Gao et al. [6] claim, because even when there are clearly defined goals, a particular challenge is linking goals with essential information and data, their interdependence and prioritization, because "the greatest challenge is to decide what data and information are essential and important, and what are not, and prioritize" (Technical Manager). This challenge can be linked to the challenge of defining business requirements for the improvement of operations, identified by Berman [3].

Challenges related to change management were identified, of which the most important are employee participation and the need to improve their competencies, as well as good cooperation between different organizational units. It is in line with the results Gao et al. [6], who notice that even where there is a clear will to launch DT, organizations have a problem managing the changes, or Deloitte [24], who notice the lack of digital competence in the mining industry. According to the general classification given by Westerman et al. [11], these challenges can be categorized into the challenges of execution and governance.

Although the technological challenges are noticed and analyzed by several authors $[6,8,11,22]$, the results of the research in particular point to the challenges related to the effective application of technology in the context of 1) increasing the demand for automation in all phases of data gathering, controlling, processing, reporting), 2) increasing the complexity of the process and, in particular, 3) preserving security through increased availability and rising cyber- threats. The importance of cyber threats in mining is also highlighted by Ernst \& Young [25] and Gao et al. [6].

Finally, there are the challenges related to external constraints. Gao et al. [6] also saw the challenges caused by the complex operating environment and legal regulations. In addition, the un-covertness of all micro-locations with the signal of mobile telephony reduces the possibilities of networking and access to data in real time. Significant challenges are the limitations of business partners, especially considering the limitation of access to data on machines and vendor lock-in.

\subsection{The success factors of DT in the mining enterprise}

This section presents the results of qualitative data analysis in order to get the answer to the question of RQ3: What are the success factors of the DT in the mining enterprise?

The identified success factors are grouped into four categories: people, organizational culture, technological framework and institutional framework (Table 2).

\section{Discussion}

The results of the research indicate several different factors that have a significant impact on the success of the DT initiative in mining. The human factor is crucial, especially the key people from business and IT part who, with knowledge, persistence and dedication, must show agility, leadership and a clear vision, because "there must be leadership from both sides, someone from the business side who knows what he wants to get, and someone from the IT side who knows how to achieve it" (Technical Manager).

Results further support the assertion of many authors that, regardless of the type of activity, leadership skills are a key factor in the success of DT [17,22,26], and in that sense, Ernst \& Young [25] and Deloitte [24] especially emphasize the importance of leadership in the mining industry. 
Table 1 The challenges of digital transformation in the mining enterprise

\begin{tabular}{|c|c|c|}
\hline Codes & Themes & Categories \\
\hline $\begin{array}{l}\text { - Increasing agility and flexibility at the } \\
\text { operational level } \\
\text { - Increasing demands for information and } \\
\text { analysis } \\
\text { - Identifying key information and data }\end{array}$ & $\begin{array}{l}\text { Link business } \\
\text { objectives with } \\
\text { information and data }\end{array}$ & $\begin{array}{l}\text { Operationalization of } \\
\text { business strategy }\end{array}$ \\
\hline $\begin{array}{l}\text { - Interdependence of information and data } \\
\text { - Prioritizing information by relevance }\end{array}$ & $\begin{array}{l}\text { Interdependence and } \\
\text { prioritization }\end{array}$ & \\
\hline $\begin{array}{l}\text { - Difficulties in coordination between the } \\
\text { various business OU because of various } \\
\text { objectives and priorities } \\
\text { - Elimination of inefficiency in the work of } \\
\text { other OU }\end{array}$ & $\begin{array}{l}\text { Cooperation across } \\
\text { organizational units } \\
\text { borders }\end{array}$ & Change management \\
\hline $\begin{array}{l}\text { - Increasing demands for quality and } \\
\text { timeliness of data from existing systems } \\
\text { - Up-to-date gathering and recording of } \\
\text { data on a daily basis } \\
\text { - Accuracy and completeness of data } \\
\text { - Lack of employee competence } \\
\text { - Difficulties to find and hire good IT staff }\end{array}$ & $\begin{array}{l}\text { Participation, } \\
\text { competencies and } \\
\text { experience of } \\
\text { employees }\end{array}$ & \\
\hline $\begin{array}{l}\text { - Efficient control of the validity and } \\
\text { quality of data } \\
\text { - Integration of data from existing systems } \\
\text { - Collect data from operational activities, } \\
\text { including data from machines }\end{array}$ & Effective automation & $\begin{array}{l}\text { Effective application of } \\
\text { technologies }\end{array}$ \\
\hline $\begin{array}{l}\text { - Effective and efficient data entry } \\
\text { - Effective reporting } \\
\text { - Integration of existing and external data } \\
\text { sources }\end{array}$ & $\begin{array}{l}\text { Complexity of the } \\
\text { process }\end{array}$ & \\
\hline $\begin{array}{l}\text { - Restrict access to data and information } \\
\text { - Availability of information - anytime, } \\
\text { anywhere }\end{array}$ & $\begin{array}{l}\text { Security and } \\
\text { availability }\end{array}$ & \\
\hline $\begin{array}{l}\text { - Duplication of data due to paper and } \\
\text { electronic records }\end{array}$ & Legal constraints & External constraints \\
\hline $\begin{array}{l}\text { - Restricted access to data on the machines } \\
\text { by the manufacturer } \\
\text { - Vendor lock-in } \\
\text { - Influence of subcontractors' short-term } \\
\text { interests on the process }\end{array}$ & $\begin{array}{l}\text { Business partners' } \\
\text { constraints }\end{array}$ & \\
\hline $\begin{array}{l}\text { - Extreme working conditions } \\
\text { (temperature, humidity, dust, mud) } \\
\text { - Inaccessibility of the terrain }\end{array}$ & $\begin{array}{l}\text { Environmental } \\
\text { constraints }\end{array}$ & \\
\hline $\begin{array}{l}\text { - Non-coverage of all micro-locations by } \\
\text { the signal of mobile telephony }\end{array}$ & $\begin{array}{l}\text { Communication } \\
\text { constraints }\end{array}$ & \\
\hline
\end{tabular}


Table 2 The success factors of digital transformation in the mining enterprise

\begin{tabular}{|c|c|c|}
\hline Codes & Themes & Categories \\
\hline $\begin{array}{l}\text { - Engagement of key people from business and IT } \\
\text { - Leadership from the business and IT side } \\
\text { - Setting clear and achievable goals aligned with the } \\
\text { business strategy }\end{array}$ & $\begin{array}{l}\text { Leadership and a } \\
\text { clear vision }\end{array}$ & \multirow[t]{2}{*}{ People } \\
\hline $\begin{array}{l}\text { - Knowledge, persistence and commitment of key } \\
\text { people from business and IT } \\
\text { - Fast delivery of functionality by IT and quick } \\
\text { feedback from business users }\end{array}$ & $\begin{array}{l}\text { Competence, com- } \\
\text { mitment and agility }\end{array}$ & \\
\hline $\begin{array}{l}\text { - Timeliness in the recording of data on a daily basis } \\
\text { - Intensive, direct communication and quick resolu- } \\
\text { tion of data discrepancies }\end{array}$ & $\begin{array}{l}\text { Discipline and } \\
\text { professionalism }\end{array}$ & \multirow[t]{2}{*}{$\begin{array}{l}\text { Organizationa } \\
\text { culture }\end{array}$} \\
\hline $\begin{array}{l}\text { - Excellent communication between business and IT } \\
\text { - Excellent coordination between business units }\end{array}$ & $\begin{array}{l}\text { Communication and } \\
\text { coordination }\end{array}$ & \\
\hline $\begin{array}{l}\text { - Good network infrastructure (LAN, WAN) } \\
\text { - Private cloud }\end{array}$ & IT infrastructure & \multirow[t]{4}{*}{$\begin{array}{l}\text { Technological } \\
\text { framework }\end{array}$} \\
\hline $\begin{array}{l}\text { - Simplicity and speed of software usage } \\
\text { - High degree of personalization and parameteriza- } \\
\text { tion }\end{array}$ & $\begin{array}{l}\text { User-tailored } \\
\text { software solution }\end{array}$ & \\
\hline $\begin{array}{l}\text { - Availability and accessibility } \\
\text { - Possibility of using mobile devices }\end{array}$ & $\begin{array}{l}\text { Mobile-first, } \\
\text { cloud-first approach }\end{array}$ & \\
\hline $\begin{array}{l}\text { - Gathering data as close to the source as possible } \\
\text { - The early detection and elimination of data errors } \\
\text { - Increasing the level of automation in the collection, } \\
\text { recording and control of data }\end{array}$ & $\begin{array}{l}\text { Speed and quality of } \\
\text { data coverage }\end{array}$ & \\
\hline $\begin{array}{l}\text { - Eliminate the need for duplication of records } \\
\text { - Application of digital technologies in order to in- } \\
\text { crease safety and security }\end{array}$ & Legislation & $\begin{array}{l}\text { Institutional } \\
\text { framework }\end{array}$ \\
\hline
\end{tabular}

In direct relation with leadership is the organizational culture, which must support discipline and professionalism when it comes to tasks, with better communication and cooperation in all parts of the organization, especially between business and IT. These results are consistent with the prevailing attitudes, because Erjavec et al. [8], Pflaum \& Gölzer [10] and Osmundsen et al. [15] emphasize the importance of organizational culture for success DT, while Ernst \& Young [24] emphasize its importance in the mining companies. Thereby, it is necessary to have in mind complex inter-relationship between the organizational structure and culture in mining enterprises [35].

Although Raab [7] in the DT process gives primacy to business transformation in relation to technology, bearing in mind the increasing importance of data as a strategic resource [23], the adoption of new, innovative technologies and their adequate application is one of the key success factors of the DT initiative. Research results point to the growing importance of IT infrastructure and technology that from the beginning supports the development and implementation of user-tailor-made software systems designed to work in cloud-based production environments and the use of mobile devices, supporting the so-called mobile-first, cloud-first approach [36].

In this regard, the role of technology for effective, automated data capture, quality control, storage and data processing is very important in order to receive important, useful information in a timely manner. Accordingly, the obtained results are somewhat in contradiction with Deloitte's position, because the success of DT in the mi- 


\section{CONCLUSIONS AND FUTURE WORK}

ning industry may not depend on the adoption of the latest applications and technologies [24], but largely depends on the adequate application of technologies that have reached a sufficient maturity level.

Finally, in order to exploit the full potential of digital technology in the mining industry, it is necessary for the competent institutions to support the process of digitalization in mining in order to identify the possibilities for increasing the safety of employees, more efficient collection and storage of data related to the realization of the operational activities of mining companies.

\section{RESEARCH LIMITATIONS}

Three limitations of the research should be taken into account. First, the research is based on the case of the realization of the DT initiative in the context of the development of business software in one mining enterprise. For this reason, a descriptive case study was first realized, with the aim of better understanding the observed phenomenon in its natural environment by examining the context, motivation, initiators, purpose, goals, results, advantages and disadvantages of the DT initiative, followed by an explorative case study, in order to identify the challenges and success factors of the DT initiative in a given context and identify the possibilities for further research. Secondly, one of the authors has played a significant role in the implementation of the DT initiative at various positions in the Company Boksit. For this reason, more researchers are involved in planning and implementing research to reduce the risk of bias. Third, the research is based on qualitative data, so different qualitative data sources, including documents, realized analytical business software system, instructions, and semi-structured interviews were used for qualitative analysis.
Digital transformation in the mining industry is an irreversible process due to great opportunities, from increasing productivity to cost reduction [19]. However, regardless of the great potential for growth in the future [24], the current state of digital transformation in mining is at a rather low level [37].

This paper presents the results of an empirical research that describe and discuss key aspects related to the initiation and effective realization of the DT initiative in the mining enterprise, in the context of the development and implementation of the analytical business software system for the improvement of operations, as well as the identified challenges and success factors in a given context. The results of the conducted empirical research point to the inevitability of digitization and the significance of the DT initiative in the mining industry, whereby the effective realization of the DT initiative, such as the development and implementation of an analytical software system based on cloud and mobile technologies, can significantly contribute to the improvement of the operational model in the mining enterprise.

The results confirm that in the realization of the DT initiative mining enterprise faces significant challenges, which are clearly defined and classified. These challenges are not only technology related, given the complexity of processes, automation, and security, but also for the operationalization of a business strategy, in particular in linking goals with interdependent information and data. In addition, significant challenges are related with change management, especially when it comes to competencies and employee cooperation across organizational boundaries, and external constraints regarding relationships with business partners, extreme working environment, legal regulations, and communication issues. 
In order to meet the challenges, success factors of the DT initiative in the mining enterprise have been identified. The identified success factors, above all, include leadership capabilities and vision of key people from business and IT, as a prerequisite for initiating and implementing the DT initiative, as well as participation, competence, commitment and agility of employees. However, success factors are not only related to people, but also to an organizational culture that, on the one hand, should promote professionalism and discipline, and on the other, good communication, cooperation and solidarity. In addition, an adequate technology framework based on the high-quality IT infrastructure, user-defined software solutions that are intrinsically linked to mobile and cloud technologies must be built to support fast and high-quality data coverage, processing and reporting. On the other hand, in order to exploit the full potential of digital technologies in the mining companies, an appropriate institutional framework is needed, which, with amendments to the legislation in the direction of greater support for the digitization process in mining, could become a catalyst for the digitization process in the mining industry.

Research contributions are a better understanding of the DT phenomenon, in general, and in particular in the context of the possibility of initiating and implementing the DT initiative in the mining industry, as well as identifying significant challenges and success factors of the DT initiative in mining companies. The results of the research will contribute to the discussion about the importance and necessity of DT, especially in the mining industry, in order to increase the efficiency of the process, reduce costs, and increase productivity and employees safety. Also, research results can help management and IT personnel in mining companies to more easily initiate and more effectively implement DT initiatives, specifically related to the improvement of the operational model.
Bearing in mind the small number of research on the subject of DT in mining, in order to overcome the gap of digital disconnection [25], additional empirical research is needed on examples of successful and unsuccessful implementations of the DT initiatives in the mining industry under conditions of surface and/or underground exploitation. Starting from the identified challenges and success factors, the possibilities of using digital technologies should be further explored in order to increase the level of automation in the coverage, control and archiving of data, as well as the possibilities for acquiring new knowledge by applying methods and techniques of AI for processing large amounts of data collected from operations.

\section{REFERENCES}

[1] World Economic Forum \& Accenture, Digital Transformation Initiative (2017), https://www.accenture.com/t20170116 T084450_w_/us-en/_acnmedia/ Accenture / Conversion-Assets/WEF/ PDF/Accenture-DTI-executivesummary.pdf (Accessed: 12 March 2018).

[2] Stolterman E. \& Fors A.C., Information technology and the good life. Information systems research (2004) 687-692.

[3] Berman S.J., Digital transformation: opportunities to create new business models, Strategy \& Leadership 40, no. 2 (2012) 16-24.

[4] Konde P. \& Tundalwar P. R., Agile Approach-Digital Transformation, International Journal of Research in Engineering, Technology and Science, Vol. VIII, Issue IV (2018) 1-8.

[5] Zimmermann A., Schmidt R., Sandkuhl K., Jugel D., Bogner J., \& Möhring M., Evolution of enterprise architecture for digital transformation, IEEE $22^{\text {nd }}$ International Enterprise 
Distributed Object Computing Workshop (2018) 87-96.

[6] Gao S., Hakanen E., Töytäri P. \& Rajala R., Digital transformation in asset-intensive businesses: Lessons learned from the metals and mining industry, Proceedings of the $52^{\text {nd }}$ Hawaii International Conference on System Sciences (2019) 4927-4936.

[7] Raab M. \& Griffin-Crya B., Digital Transformation of Supply Chains: Creating Value - When Digital Meets Physical, Capgemini Consulting (2011).

[8] Erjavec J., Manfreda A., Jaklič J., Štemberger M.I., Fehér P., Szabó Z. and Kö A., Case Studies of Successful Digital Transformation in Slovenia And Hungary, $5^{\text {th }}$ International Conference on Management and Organization (2018) 1-11.

[9] Liere-Netheler K., Vogelsang K., Packmohr S. and Hoppe U., Towards a Framework for Digital Transformation Success in Manufacturing, European Conference on Information Systems (2018) 1-19.

[10] Pflaum A.A. and Gölzer P., The IoT and digital transformation: toward the data-driven enterprise. IEEE Pervasive Computing, 17(1) (2018) 87-91.

[11] Westerman G., Calméjane C., Bonnet D., Ferraris P. and McAfee A., Digital Transformation: A roadmap for billion-dollar organizations. MIT Center for Digital Business and Capgemini Consulting, 1 (2011) 1-68.

[12] Fitzgerald M., Kruschwitz N., Bonnet D. and Welch M., Embracing digital technology: A new strategic imperative, MIT sloan management review, 55(2) (2014) 1.

[13] Henriette E., Feki M. and Boughzala I., The shape of digital transformation: A systematic literature review. MCIS 2015 Proceedings (2015) 431-443.
[14] Nahrkhalaji S.S., Shafiee S., Shafiee M. and Hvam L., December. Challenges of Digital Transformation: The case of the Non-Profit Sector, In 2018 IEEE International Conference on Industrial Engineering and Engineering Management (IEEM) (2018) 1245-1249.

[15] Osmundsen K., Iden J. and Bygstad B., 2018. Digital Transformation: Drivers, Success Factors, and Implications, MCIS 2018 Proceedings (2018) 37.

[16] Sahu N., Deng H. and Mollah A., Investigating the Critical Success Factors of Digital Transformation for Improving Customer Experience. International Conference on Information Resources Management (2018) $1-13$.

[17] Westerman G., Bonnet D. \& McAfee A., Leading digital: Turning technology into business transformation, Boston, Massachusetts, Harvard Business Press, 2014, 9-26.

[18] Lammers T., Tomidei L. and Regattieri A., What Causes Companies to Transform Digitally? An overview of drivers for Australian key industries, Portland International Conference on Management of Engineering and Technology (PICMET) (2018) 1-8.

[19] Singh, A., Singh, U.K. and Kumar, D., IoT in mining for sensing, monitoring and prediction of underground mines roof support, $4^{\text {th }}$ International Conference on Recent Advances in Information Technology (RAIT) (2018)1-5.

[20] de Sousa J.S., Rocha I.O. and de Castro R.M., Digital Transformation Applied to Bauxite and Alumina Business System-BABS 4.0, Proceedings of $37^{\text {th }}$ International ICSOBA Conference (2018) 119-132.

[21] Wolf M., Semm A. and Erfurth C., Digital transformation in companieschallenges and success factors, 
International Conference on Innovations for Community Services (2018) 178-193.

[22] Earley S., The digital transformation: staying competitive, IT Professional 16(2) (2014) 58-60.

[23] De Carolis A., Macchi M., Negri E. and Terzi S., Guiding manufacturing companies towards digitalization a methodology for supporting manufacturing companies in defining their digitalization roadmap. International Conference on Engineering, Technology and Innovation (ICE/ITMC) (2017) 487-495.

[24] Deloitte, Tracking the trends 2018. The top 10 issues shaping mining in the year ahead.

https://www2.deloitte.com/content/da $\mathrm{m} /$ Deloitte/global/Documents/Energyand-Resources/gx-TTT-report-2018. PDF (Accessed: 12 November 2018).

[25] Ernst \& Young, The digital disconnect: problem or pathway? (2017) 1-12. http://www.ey.com/Publication/vwLU Assets/EY-the-digital-disconnectproblem-or-pathway/\$FILE/EYdigital-disconnect-in-mining-andmetals.pdf. (Accessed: 12 November 2018).

[26] Khan S., Leadership in the digital age - A study on the effects of digitalization on top management leadership (thesis), Stockholm University (2016) p. 54.

[27] Sebastian I., Ross J., Beath C., Mocker M., Moloney K. \& Fonstad N., How Big Old Companies Navigate Digital Transformation, MIS Quarterly Executive, September (2017), 197-213.

[28] Liu D.Y., Chen S.W. \& Chou T.C., Resource fit in digital transformation: Lessons learned from the CBC Bank global e-banking project, Management Decision, 49(10) (2011) 1728-1742.
[29] Zhou T., Examining the critical success factors of mobile website adoption, Online Information Review, 35(4) (2011) 636-652.

[30] Astri L.Y., A Study Literature of Critical Success Factors of Cloud Computing in Organizations, Procedia Computer Science. Elsevier Masson SAS, 59(Iccsci) (2015) 188-194.

[31] Yin R.K., Case Study Research: Design and Methods, London, Sage Publications, 2003, p. 53.

[32] Eisenhardt K. M., \& Graebner M. E., Theory building from cases: Opportunities and challenges, Academy of management journal 50(1) (2007) 25-32.

[33] Berghaus S., \& Back A., Disentangling the fuzzy front end of digital transformation: Activities and approaches, Association for Information Systems (2017).

[34] Porter M.E. and Heppelmann J.E., How smart, connected products are transforming companies, Harvard business review 93(10) (2015) 96-114.

[35] Paunković J., Jovanović V. and Žikić S., Relationship between the organizational structure and culture: Case studies of the mining companies in Serbia. Mining and Metallurgy Engineering Bor, (1-2) (2018) 137-144.

[36] Nadella S., Mobile First. Cloud First Press Briefing.

https://news.microsoft.com/2014/03/27 /satya-nadella-mobile-first-cloud-firstpress-briefing. (Accessed: 12 November 2018).

[37] EU Digital Economy and Society Index Report (2018),

http://ec.europa.eu/newsroom/dae/doc ument.cfm?doc_id=52243. (Accessed: 1 February 2019). 